\title{
HEPATITIS AUTOINMUNE EN UN PACIENTE CON COROIDITIS SERPIGINOSA
}

\section{AUTOIMMUNE HEPATITIS IN A PATIENT WITH SERPIGINOUS CHOROIDITIS}

\author{
GÓMEZ-MAESTRA MJ ${ }^{1}$, FRANCÉS E ${ }^{2}$, AUSÍN E ${ }^{1}$, MARTÍNEZ-COSTA R ${ }^{2}$
}

\section{RESUMEN}

Caso clínico: Presentamos el caso clínico de una paciente afecta de coroiditis serpiginosa que presentó un cuadro de hepatitis autoinmune.

Discusión: La etiología de la coroiditis serpiginosa permanece desconocida. Se ha postulado una anormal respuesta de sistema inmunitario como mecanismo. Este caso muestra la asociación de la coroiditis serpiginosa con un proceso de tipo autoinmune.

Palabras clave: Coroiditis serpiginosa, hepatitis autoinmune, autoinmunidad, esteroides, coriocapilar.

\section{INTRODUCCIÓN}

La coroiditis serpiginosa es una rara enfermedad inflamatoria que afecta a la coriocapilar y al epitelio pigmentario de la retina (EPR). También se la conoce como coroiditis geográfica helicoidal peripapilar por los típicos hallazgos clínicos. Generalmente afecta a ambos ojos, pero puede ser asimétrica. Presenta un curso lentamente progresivo, con múltiples recurrencias. Suele presentarse en forma de visión borrosa y escotomas paracentrales (1).

\begin{abstract}
Case report: We report the case of a patient with serpiginous choroiditis who developed an autoinmune hepatitis.

Discussion: The etiology of serpiginous choroiditis remains uncertain. An immune-mediated mechanism has been reported. This case shows an association between serpiginous choroiditis and autoimmune processes (Arch Soc Esp Oftalmol 2007; 82: 773-776).
\end{abstract}

Key words: Serpiginous choroiditis, autoimmune hepatitis, autoimmunity, steroids, choriocapillaris.

Es ligeramente más prevalente en varones y la edad de presentación suele estar entre los 30 y los 70 años. En ausencia de tratamiento el pronóstico es malo debido a la afectación macular.

Las lesiones generalmente empiezan en la papila y se diseminan de forma serpenteada hacia fuera y hacia la mácula. Las lesiones agudas son infiltrados subretinianos de color gris-amarillo. A medida que las lesiones avanzan se produce cicatrización coriorretiniana con hipertrofia variable del EPR, atrofia progresiva y fibrosis. La neovascularización coroi-

\footnotetext{
Recibido: 31/5/06. Aceptado: 30/10/07.

Servicio de Oftalmología. Hospital Universitario La Fe. Valencia. España.

1 Licenciado en Medicina.

2 Doctor en Medicina.

Correspondencia:

María J. Gómez Maestra

Hospital Universitario La Fe

Servicio de Oftalmología

Avda. Campanar, 19

46009 Valencia

España

E-mail: yesigomezmaestra@ hotmail.com
} 
dea ocurre entre un $10 \%$ y un $25 \%$ de los pacientes. Las lesiones recidivantes aparecen contiguas o de forma satélite a las antiguas cicatrices.

El diagnóstico se basa en hallazgos clínicos. La angiografía fluoresceínica (AGF) es bastante útil. Las lesiones agudas presentan en la fase temprana hipofluorescencia del centro de las lesiones e hiperfluoresencia del reborde de las lesiones. En la fase tardía aparece hiperfluorescencia. Las lesiones inactivas presentan hipofluorescencia con tinción tardía. La angiografía con verde de indocianina también es útil para detectar lesiones activas (2).

El tratamiento (3) que se ha demostrado más efectivo incluye una triple terapia con corticoides sistémicos, azatioprina y ciclosporina, aunque puede ser adecuada una monoterapia precoz con ciclosporina.

\section{CASO CLÍNICO}

Mujer de 62 años que refiere, desde hace 13 años, múltiples episodios de visión borrosa en ambos ojos con recuperación posterior completa de la agudeza visual. Los diversos brotes que presentó fueron tratados con corticoterapia oral, suspendiéndose los mismos tras las respectivas remisiones. Fue diagnosticada de coroiditis serpiginosa por los hallazgos clínicos y angiográficos.

Como antecedentes familiares presenta una hermana gemela de su madre con un cuadro similar. No presenta antecedentes personales de interés.

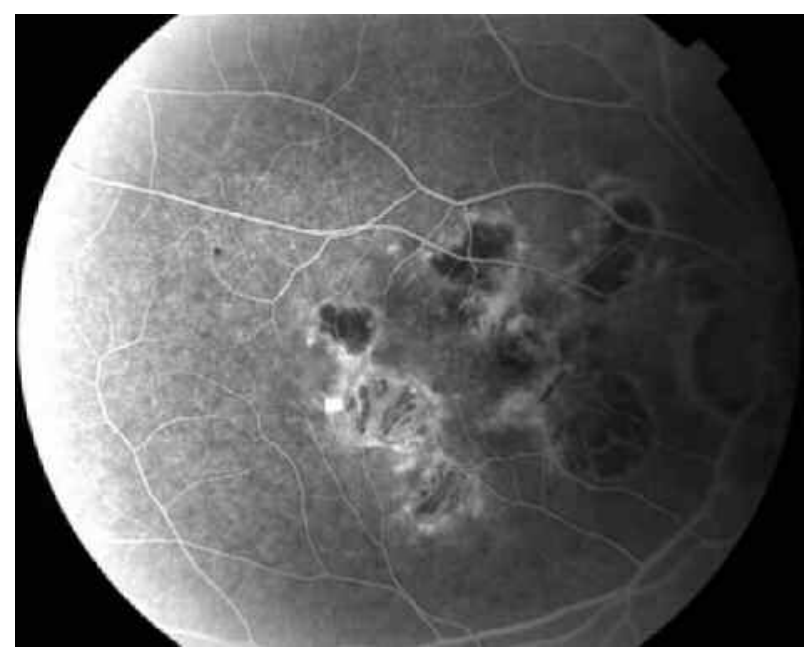

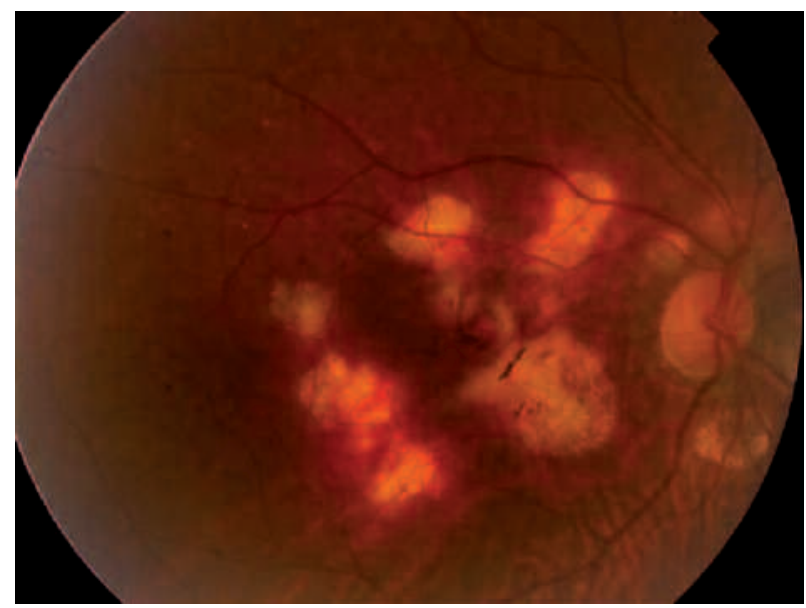

Fig. 1: El examen funduscópico del ojo derecho muestra múltiples lesiones cicatriciales y de atrofia coriorretiniana en el polo posterior y peripapilares. Existe afectación de la mácula y perifóvea y a pesar de ello la paciente presente una $A V$ de 1.

En la última revisión oftalmológica la enfermedad permanecía inactiva y la agudeza visual (AV) era de la unidad en ambos ojos a pesar de la importante atrofia y cicatrización coriorretiniana que presentaba en el polo posterior, incluyendo la mácula. El segmento anterior no mostraba hallazgos relevantes y la presión intraocular era de $14 \mathrm{mmHg}$ en ambos ojos.

El fondo de ojo presentaba múltiples lesiones de forma geográfica cicatriciales, con atrofia e hipertrofia variable del EPR en todo el polo posterior (figs. $1 \mathrm{y}$ 4).

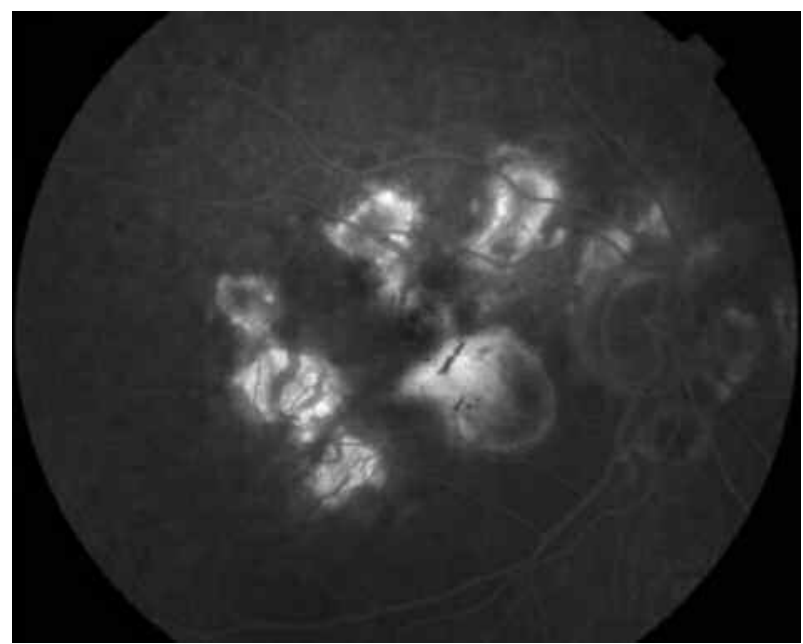

Fig. 2 y 3: La AGF del ojo derecho muestra inactividad de las lesiones con hipofluoresencia en fases precoces y tinción de las lesiones en fases tardías. 
La angiografía fluoresceína mostraba múltiples lesiones de aspecto moteado debido a atrofia e hiperpigmentación, con tinción en fases tardías (figs. 2, 3, 5 y 6).

Cuatro meses antes comenzó un cuadro de dispepsia flatulenta, vómitos y prurito. En los estudios de laboratorio realizados presenta un aumento de las transaminasas (GOT 110 y GPT 90), GGT (gammaglutamiltranspeptidasa) 110, hipergammaglobulinemia (IgG 1620), ANA (Anticuerpos antinucleares) 1/320, AMA (Anticuerpos antimitocondriales) negativos.

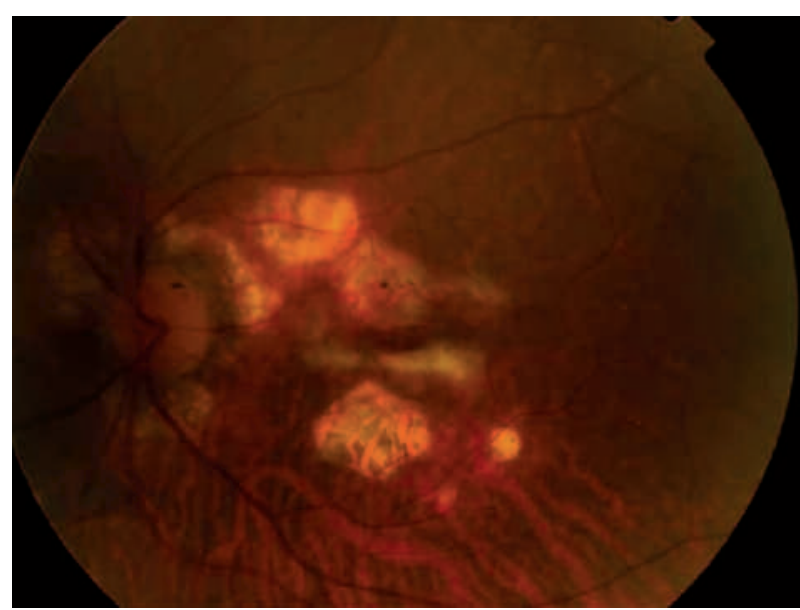

Fig. 4: El examen funduscópico del ojo izquierdo muestra lesiones similares que el ojo derecho, y la paciente también presenta una $A V$ de 1.

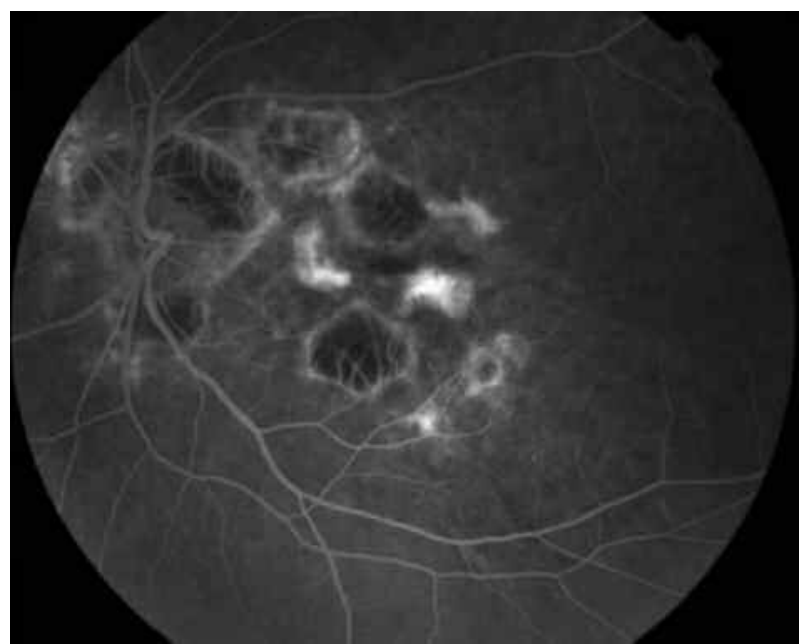

Antígeno de superficie VHB, Anticuerpo anti$\mathrm{HBs}$, Anticuerpo anti-HBc y Anticuerpo anti-VHC negativos. Se realizó una ecografía hepática que fue normal.

El cuadro tuvo una buena respuesta a los ácidos biliares calculolíticos. El diagnóstico de sospecha fue de hepatitis autoinmune. Se decidió no realizar pruebas diagnósticas agresivas como una biopsia hepática debido a la actividad leve del cuadro digestivo.

\section{DISCUSIÓN}

La etiología de la coroiditis serpiginosa (CS) permanece desconocida, si bien existe la hipótesis de que pudiera estar causada por una anormal respuesta del sistema inmunitario. Se ha encontrado un aumento en la frecuencia de presentación del HLAB7 y asociaciones con el antígeno $\mathrm{S}$ retiniano. También se ha postulado una posible asociación con los virus Herpes (1).

Asimismo se encontró una elevación del factor VIII de von Willebrand en una pequeña serie de pacientes que fueron estudiados.

La histopatología de las lesiones coriorretinianas de la CS muestra infiltrados difusos y focales de linfocitos en la coroides. El infiltrado es mayor en los márgenes de las lesiones, que son las zonas más activas.

Este caso clínico muestra la presentación de una hepatitis autoinmune en una paciente con CS de lar-

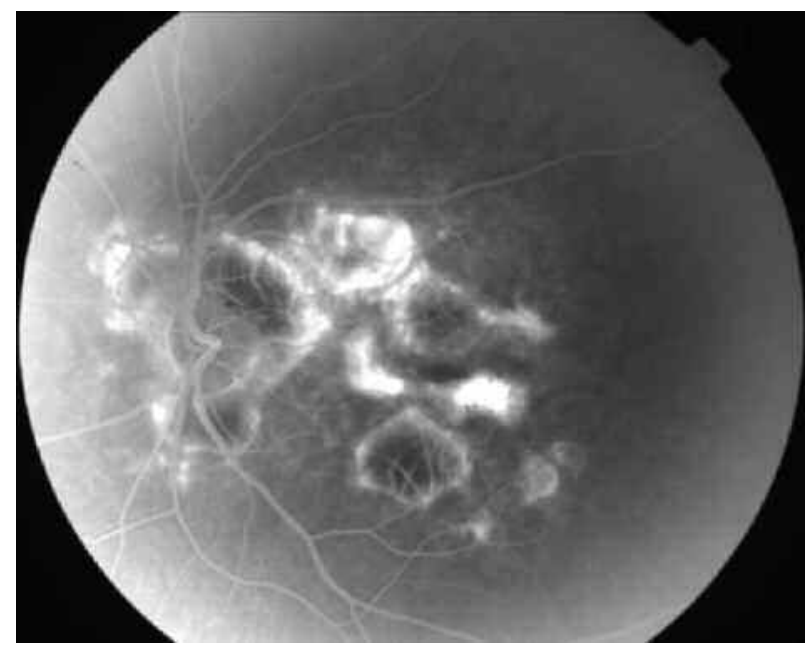

Fig. 5 y 6: La AGF del ojo izquierdo muestra lesiones inactivas, con hipofluorescencia en fases precoces e hiperfluorescencia en fases tardías. 
go tiempo de evolución. Una anormal respuesta del sistema inmune de esta paciente pudo originar ambos procesos. Fuentes-Paez et al. (4) presentaron el caso de una paciente con Lupus Eritematoso Sistémico clínicamente estable que desarrolló una CS. Santos-Bueso et al. (5) describieron el caso de una paciente diagnosticada de CS que tres meses antes presentó coinfección por virus de la hepatitis B y C. En este último caso, no se trata de la aparición de una enfermedad autoinmune asociada a la CS, sino que la existencia de una serie de antígenos virales podrían desencadenar un trastorno inmunológico que finalmente condujera a la aparición de una lesión retiniana. En ninguno de los tres casos se puede descartar la posible casualidad de esta asociación. Estos casos apoyarían la hipótesis de que una alteración inmunológica cause las lesiones inflamatorias retinianas características de la CS.

\section{BIBLIOGRAFÍA}

1. Quillen DA, Davis JB, Gottlieb JL, Blodi BA, Callanan $D G$, Chang TS, et al. The white dot syndromes. Am J Ophthalmol 2004; 137: 538-550.

2. Lleó Pérez A, Hernández Pérez D, Hernández Martínez FJ, Navarro Palop C, Marcos Jorge A, Pallás Ventayol C. Manifestaciones clínicas y angiográficas en tres pacientes con coroiditis serpiginosa. Arch Soc Esp Oftalmol 2000; 75: 555-558.

3. Marcuello Melendo B, Torron Fernández-Blanco C, Perez Olivan S, Ruiz Moreno O, Ferrer Novella E, Honrubia López FM. Coroiditis serpiginosa: evolución clínica y tratamiento. Arch Soc Esp Oftalmol 2004; 79: 237-242.

4. Fuentes-Paez G, Celis-Sanchez J, Torres J, Martinez-Osorio $H$, Herreras JM. Serpiginous coroiditis in a patient with systemic lupus erythematosus. Lupus 2005; 14: 928929.

5. Santos-Bueso E, Calvo-Gonzalez, C, Reche-Frutos J, Díaz Valle D. Coroiditis serpiginosa y coinfección por virus de hepatitis B y C. Studium Ophthalmologicum 2006; 24: 31 34. 